\title{
Editorial Volume 10 Número 1 Junho de 2015
}

A Gestão \& Tecnologia de Projetos publica sua primeira edição de 2015, inaugurando o décimo ano de publicação da revista que teve seu primeiro número lançado em novembro de 2006.

Ao longo desse tempo, o periódico vem cumprindo sua função de colaborar com as discussões em torno de tecnologias e métodos inovadores referentes à metodologia, gestão, avaliação e ensino do processo de projeto no ambiente construído.

Continua vigente seu objetivo de colaborar com os debates em torno da qualidade do projeto, mais ainda nesse momento em que a construção civil brasileira atravessa um cenário de incerteza, no qual a competitividade de empresas e empreendimentos passa pela melhoria do processo de projeto.

A partir deste ano a revista passa a publicar três números por ano de forma a incrementar o número de trabalhos publicados e encurtar os prazos entre o aceite e a publicação das contribuições recebidas. Para realizar a transição de dois para três números anuais, temos em 2015 a publicação deste número de meio de ano e dois números programados para novembro e dezembro. A partir de 2016 a revista passa a publicar em intervalos quadrimestrais.

Essa primeira edição de 2015 encarta trabalhos que revelam mais uma vez a multiplicidade de temas e focos assumidos por pesquisadores brasileiros da área, com destaque para linhas de pesquisa que estão na atual arena de debates: o uso de BIM no processo de projeto, o desenvolvimento de métodos de técnicas de avaliação pós-ocupação e a reflexão sobre os processos de coordenação de projetos. São três linhas temáticas que sempre estiveram presentes nesse periódico.

O primeiro trabalho, "Restrições orçamentárias e entrega de valor: sinergias entre BIM e custeio-meta", desenvolvido por pesquisadores da Universidade Estadual de Campinas (Unicamp), apresenta uma revisão crítica da literatura mostrando as oportunidades de uso do BIM no levantamento e processamento de informações utilizadas como suporte aos trabalhos de custeio-meta, na fase inicial de concepção dos empreendimentos.

O segundo trabalho, desenvolvido por pesquisadores da Universidade Estadual de Londrina (UEL), apresenta um estudo exploratório que confronta o desempenho de protótipos na análise de inconsistências de projetos, comparando protótipos físicos com modelos analíticos 2D e 3D, esses últimos produzidos a partir do BIM.

O terceiro trabalho foi desenvolvido no âmbito da Universidade Federal de Minas Gerais (UFMG) e apresenta um estudo exploratório sobre o processo de projeto de reformas em edifícios de uma instituição universitária pública, destacando sua complexidade em função de características peculiares do processo de projeto nesse tipo de instituição.

O quarto trabalho, "Avaliação Pós-Ocupação: pré-teste de instrumentos para verificação do desempenho de empreendimentos habitacionais em sistemas construtivos inovadores", desenvolvido por pesquisadores da Faculdade de Arquitetura e Urbanismo da Universidade de São Paulo (FAU-USP), destaca a associação de métodos de avaliação pós-ocupação e de instrumentos de avaliação técnica de desempenho para avaliar sistemas construtivos inovadores em habitações de interesse social, considerando parâmetros estabelecidos pela NBR 15575, de 2013.

O quinto trabalho também concentra sua atenção em mecanismos de avaliação pós-ocupação, destacando o uso da técnica de preferencia declarada na avaliação de habitações de interesse social no âmbito do Programa Minha Casa Minha Vida.

Por último, o trabalho "Integrated design of industrialized building systems: the technology center of the Sarah Network - CTRS, Brasil”, em língua inglesa, resgata 
o tema da gestão do processo de projeto, estudando-o em edificações que utilizam princípios de industrialização. Esse estudo foi realizado em um empreendimento do conhecido arquiteto João Figueiras Lima, também conhecido como Lelé. Desejamos a todos uma excelente leitura.

Prof. Dr. Paulo Roberto Pereira Andery

Prof. Dr. Márcio Minto Fabricio 